\title{
Divergence Between Sympatric Rice- and Soybean-Infecting Populations of Rhizoctonia solani Anastomosis Group-1 IA
}

\author{
Joana Bernardes de Assis, Patrik Peyer, Milton C. Rush, \\ Marcello Zala, Bruce A. McDonald, and Paulo C. Ceresini
}

First, second, fourth, fifth, and sixth authors: Plant Pathology, Institute of Integrative Biology, ETH Zurich, Switzerland; third author: Plant Pathology and Crop Physiology Department, Louisiana State University AgCenter; and sixth author: UNESP, Campus de Ilha Solteira, Depto. de Fitossanidade, Engenharia Rural e Solos, 15385-000, Ilha Solteira, SP, Brazil. Accepted for publication 20 August 2008.

\begin{abstract}
Bernardes de Assis, J., Peyer, P., Rush, M. C., Zala, M., McDonald, B. A., and Ceresini, P. C. 2008. Divergence between sympatric rice- and soybean-infecting populations of Rhizoctonia solani anastomosis group-1 IA. Phytopathology 98:1326-1333.

Rhizoctonia solani anastomosis group (AG)-1 IA causes soybean foliar blighting (aerial blight) and rice sheath blight diseases. Although taxonomically related within the AG-1 complex, sister populations of $R$. solani AG-1 IA infecting Poaceae (rice) and Fabaceae (soybean) are genetically distinct based on internal transcribed spacer rDNA. However, there is currently no information available regarding the extent of genetic differentiation and host specialization between rice- and soybean-infecting populations of $R$. solani AG-1 IA. We used 10 microsatellite loci to

lates were shared among the three populations. Partitioning of genetic diversity showed significant differentiation among sympatric populations from different host species $\left(\Phi_{\mathrm{ST}}=0.39\right.$ to 0.41$)$. Historical migration patterns between sympatric rice- and soybean-infecting populations from Louisiana were asymmetrical. Rice- and soybean-derived isolates of $R$. solani AG-1 IA were able to infect both rice and soybean, but were significantly more aggressive on their host of origin, consistent with host specialization. The soybean-infecting population from Louisiana was more clonal than the sympatric rice-infecting population. Most of the loci in the soybean-infecting populations were out of Hardy-Weinberg equilibrium (HWE), but the sympatric rice-infecting population from Louisiana was mainly in HWE. All populations presented evidence for a mixed reproductive system.
\end{abstract} compare sympatric $R$. solani AG-1 IA populations infecting rice and soybeans in Louisiana and one allopatric rice-infecting population from Texas. None of the 154 multilocus genotypes found among the 223 iso-
Additional keywords: pathogen emergence, soybean aerial blight.
Current evidence indicates that Rhizoctonia solani anastomosis group-1 IA (AG-1 IA) represents a single species with a broad host range (12). $R$. solani AG-1 IA is a major fungal pathogen infecting Fabaceous and Poaceous plants. It causes sheath blight and sheath spot on rice, banded leaf and sheath blight on maize, and aerial blight on soybean $(31,50)$. Two well-defined phylogenetic (sister) groups of $R$. solani AG-1 causing diseases associated with Poaceous and Fabaceous hosts were identified by nested clade analyses of internal transcribed spacer (ITS)-5.8S rDNA haplotypes (10). Isolates from the two hosts also differ in their disease biology and epidemiology. In general, Poaceaeinfecting $R$. solani AG-1 IA is considered predominantly asexual and is thought to survive as mycelium and sclerotia in soil and on seeds $(33,45)$. Although basidiospore formation in paddy rice has been frequently observed, the role of sexual spores in the disease cycle is not fully understood $(31,42,47)$. In contrast, $R$. solani AG1 IA on Fabaceae is thought to have a predominantly sexual reproductive system on its hosts, such as soybean (31), because Thanatephorus cucumeris is frequently associated with the soybean aerial blight disease $(18,19,31,61)$.

\section{Corresponding author: P. C. Ceresini; E-mail address: paulo.ceresini@agrl.ethz.ch}

* The $e$-Xtra logo stands for "electronic extra" and indicates that the online version contains five supplemental files showing the geographical origin of the populations, the allele frequency distributions and the information content associated with the ten microsatellite loci, the membership coefficient of multilocus genotypes to distinct populations, and the historical migration rates.

doi:10.1094/PHYTO-98-12-1326

(c) 2008 The American Phytopathological Society
Host specialization is common in plant-pathogenic fungi $(4,8,13,14,59)$. Within the $R$. solani complex, host specialization has already been described for Solanaceae-infecting $R$. solani AG-3 where potato- and tobacco-infecting populations represent two genetically distinct lineages (9).

Host specialization eventually leads to divergence between populations of plant pathogens (48). To infer if host specialization is the ultimate cause for the divergence, it is necessary to sample populations from nearby locations (sympatric host populations). In addition, cross inoculation tests are needed to confirm the extent of specialization. Using this sampling strategy, GonzálezVera et al. (23) recently reported the existence of two genetically distinct field populations of $R$. solani AG-1 IA infecting two Poaceous hosts (rice and maize) in Venezuela. These two groups of sympatric host populations were differentiated $\left(\Phi_{\mathrm{ST}}=0.17\right)$ and divergence was postulated to be due to host specialization, as the geographical effect on the differentiation was significantly lower $\left(\Phi_{\mathrm{ST}}=0.03\right.$ to 0.06$)$. However, the hypothesis of nospecialization could not be rejected as maize- and rice-derived isolates of $R$. solani AG-1 IA with different multilocus genotypes were cross-pathogenic to both rice and maize, and similarly aggressive.

There is currently no information available regarding the extent of genetic differentiation and host specialization between Poaceae (rice)- and Fabaceae (soybean)-infecting populations of $R$. solani AG-1 IA. Analysis of the distribution of genetic diversity within and among host distinct populations can be used to identify patterns of between-host migration and to reveal cryptic recombination, with possible implications for the effectiveness of control strategies on both hosts (39). 
Our primary goal with this study was to determine the extent of host specialization between populations of $R$. solani AG-1 IA from rice and soybeans. Populations of $R$. solani AG-1 IA from rice and soybean fields in Louisiana and Texas were compared using microsatellite markers to test the hypotheses of (i) no genetic differentiation between allopatric or sympatric Poaceaeand Fabaceae-infecting populations, and (ii) no differences in aggressiveness between rice- and soybean-derived isolates. A secondary goal was to determine the reproductive system on both hosts. We tested the null hypothesis of no differences in the reproductive system.

\section{MATERIALS AND METHODS}

Population sampling. Two sympatric geographically paired populations of $R$. solani AG-1 IA from rice and soybeans were collected from two naturally infested agricultural fields near Ville Platt and Thornwell, Louisiana. The rice field near Ville Platt in Evangeline Parish was sampled in August 2005. The soybean field near Thornwell in Jefferson Davis Parish was sampled in September 2005. Both rice and soybean fields were sampled using a transect strategy. Rice and soybean samples of 5 to 10 leaves severely attacked by sheath blight or aerial blight were collected at 10 to $15 \mathrm{~m}$ intervals across the field, along 10 transects at 80 to $100 \mathrm{~m}$ intervals. No fungicide was applied to either of the fields. While soybean in Louisiana is mainly a dry-land rain-fed crop, rice is cropped under flooded conditions $(36,41)$.

A rice-infecting population of 61 isolates of $R$. solani AG-1 IA from Texas (collected in 1994 by N. G. Whitney, Texas A\&M University Agricultural Research and Extension Center, Beaumont) was included in our study as an allopatric population. The Texas population originated from six different rice fields sampled along a few hundred kilometers, while the Louisiana populations were from two different fields separated by $80 \mathrm{~km}$. Sampling strategy, isolation of the infected material, and DNA extraction methods for those isolates from Texas were described elsewhere (54).

Isolations were made by transferring fragments of infected leaves to plates containing selective medium (32) and incubating at $25^{\circ} \mathrm{C}$ in the dark. Pure cultures of $R$. solani were established by transferring hyphal tips (following growth in the selective medium for 24 to $48 \mathrm{~h}$ ) to potato dextrose agar (PDA). Sclerotia from 5-day-old cultures from each isolate were transferred to 1.8-ml cryotubes (Nunc CryoLine System, Denmark) containing anhydrous silica gel for long-term storage at $4^{\circ} \mathrm{C}$, after 10 days incubation at $25^{\circ} \mathrm{C}$. Fungal DNA was extracted as described earlier (35). The AG of the isolates was determined by sequencing the ITS-5.8S region of each isolate and comparing with sequences from AG-1 IA isolates (22).

Microsatellite genotyping. Each isolate from the three $R$. solani populations was genotyped using a set of 10 polymorphic simple sequence repeat (SSR) loci (62) using fluorescent-labeled primers. Polymerase chain reaction (PCR) amplifications were performed in 96 well plates in a total volume of $20 \mu \mathrm{l}$ with $5 \mu \mathrm{l}$ of genomic DNA (5 to $15 \mathrm{ng}$ of final concentration), $2 \mu \mathrm{l}$ of $10 \times$ reaction buffer $\left(100 \mathrm{mM} \mathrm{KCl}, 100 \mathrm{mM}\left(\mathrm{NH}_{4}\right)_{2} \mathrm{SO}, 200 \mathrm{mM}\right.$ Tris$\mathrm{HCl}, 20 \mathrm{mM} \mathrm{MgCl}_{2}, 0.1 \%$ Triton X-100, $\mathrm{pH} 8.8$, New England Biolabs), $0.3 \mu \mathrm{M}$ of each labeled (Applied Biosystems) and nonlabeled primer (Microsynth), $0.1 \mathrm{mM}$ of each dNTP, and $0.5 \mathrm{U}$ of Taq polymerase (New England Biolabs). PCR amplifications entailed a $2.5 \mathrm{~min}$ initial denaturation step at $94^{\circ} \mathrm{C}$, followed by 35 cycles of $30 \mathrm{~s}$ each at 94,50 , and 72; and then a 5-min final extension step at $72^{\circ} \mathrm{C}$. For locus TC11, a touchdown amplification protocol (44) was used instead. The touchdown protocol included an initial denaturation step of $2.5 \mathrm{~min}$ at $96^{\circ} \mathrm{C}$, followed by 11 cycles of denaturation for $30 \mathrm{~s}$ at $96^{\circ} \mathrm{C}$, annealing for $30 \mathrm{~s}$ and elongation for $30 \mathrm{~s}$ at $72^{\circ} \mathrm{C}$; the annealing temperature dropped by $0.5^{\circ} \mathrm{C}$ each cycle, starting from $60^{\circ} \mathrm{C}$ and reaching $55^{\circ} \mathrm{C}$ in the last cycle. Then it was followed by 19 cycles of $30 \mathrm{~s}$ at $96^{\circ} \mathrm{C}, 30 \mathrm{~s}$ at $50^{\circ} \mathrm{C}, 30 \mathrm{~s}$ at $72^{\circ} \mathrm{C}$, with a final extension step of $5 \mathrm{~min}$ at $72^{\circ} \mathrm{C}$. All amplification reactions were carried out in a Biometra T-gradient thermocycler.

The fluorescent-labeled PCR products, along with a fluorescently labeled size standard (GeneScan-500 LIZ; Applied Biosystems), were electrophoresed using an ABI PRISM 3100 (Applied Biosystems) automated sequencer. As described in Zala et al. (62), five loci were run together in two distinct sets (set 1: TC01, TC02, TC03, TC05, and TC11; set 2: TC06, TC07, TC10, TC12, and TC17). Genescan and Genotyper version 3.7 software (Applied Biosystems) were used to score the size of PCR products. Two control isolates (TC05USA_KAT_C6 from soybean and TC05VNZ_A1A1 from rice) were included in every run of 94 samples. Further evidence for repeatability of the SSR markers was obtained by contrasting sizes of each allele at every locus for 33 isolates from the Louisiana rice-infecting population, which was independently genotyped twice. The data from this second independent genotyping were used to describe the microsatellite genotyping system (62). The statistical binning of the alleles into fragment size categories (consistent with the repeat unit increments in reference 62) was implemented using the program FLEXIBIN (Department of Zoology, Cambridge University, UK) (2).

Cross pathogenicity test. Six rice-infecting and six soybeaninfecting isolates of $R$. solani AG-1 IA with unique multilocus SSR haplotypes were selected randomly for this test. The fungal inoculum was produced on PDA plates (amended with kanamycin at $50 \mu \mathrm{g} / \mathrm{ml}$ ) by transferring $10 \mathrm{~g}$ of sterilized parboiled rice grains to the top of a 4-day-old fungal colony and incubating for 5 days at room temperature. Greenhouse-grown 6-month-old rice plants from cultivar Koshihikari and 28-day-old soybean plants from cultivar Fiskeby were the source of detached plant tissue. Rice plants were cut approximately $3 \mathrm{~cm}$ above and $6 \mathrm{~cm}$ below the sheath; soybean leaves were cut at the petiole. A piece of cotton was attached to the lower cut of the detached rice sheaths and to the petiole of detached soybean leaves. Detached rice or soybean tissue was placed into a petri dish containing $3 \mathrm{ml}$ of distilled water. Plant tissue was inoculated by transferring one colonized rice grain to the center of the rice sheath or detached soybean leaf. Noncolonized rice grains were used to inoculate the controls. Inoculated tissue was incubated for 5 days at $25^{\circ} \mathrm{C}$ at room temperature. The test was split into two experiments: (i) inoculation onto rice tissue and (ii) inoculation onto soybean tissue. The experiments were arranged in a completely randomized block design, with five replications. To check reproducibility, two riceand two soybean-derived isolates chosen at random from the 12 isolates (plus one control for each plant species) were inoculated in a separate experiment that was replicated twice. After a 5-day incubation period, high-resolution images were captured and the extent of infection was measured using the diseased tissue area as described below.

Data analysis: Microsatellite information content. In all analyses we assumed that $R$. solani AG-1 IA is a functional diploid (i.e., it is a dikaryon). All of our data were consistent with this assumption. Data on the range of repeats for each locus, number of alleles, identification of private alleles (i.e., those present in only one population), and allelic frequencies were assessed using the program CONVERT version 1.31 (Purdue University, West Lafayette, IN) (21). The complete allele frequency distributions of the 10 microsatellite loci in the rice- and soybeaninfecting populations from Texas and Louisiana are available in supplementary files.

Genotype diversity. A microsatellite multilocus genotype for each strain was determined using the program GENOTYPE (Institute for Biodiversity and Ecosystem Dynamics, Universiteit van Amsterdam, Amsterdam, the Netherlands) (40). Isolates with the same multilocus SSR genotype were treated as clones. Several 
indices of clonal diversity were calculated, including (i) the number of genotypes per population; (ii) the clonal fraction (or the proportion of fungal isolates originating from asexual reproduction), calculated as $1-$ [(number of different genotypes)/(total number of isolates)] (63); (iii) both the Stoddart and Taylor's genotypic diversity $G_{o}=1 / \Sigma p_{i}^{2}$, where $p_{i}$ is the frequency of the $i$ th genotype (59), and its evenness ( $G_{o}$ scaled by the maximum number of expected genotypes), an indicator for how evenly the genotypes are distributed over the population. These measures were calculated using the program GENODIVE (Institute for Biodiversity and Ecosystem Dynamics, Universiteit van Amsterdam, Amsterdam, the Netherlands) (40). To test whether pairs of populations differed in their clonal diversity, we used a bootstrapping approach (resampling with replacement), where the individuals were resampled from the populations and the diversity indices were compared after every replicate (37), using 1,000 permutations with subsampling to match the size of the smallest population (25).

Gene diversity and differentiation among host populations. These analyses were performed on the clone-corrected data set in which only one individual of each multilocus SSR genotype was included per population. Nei's unbiased gene diversity was estimated as $\mathrm{n} /(\mathrm{n}-1) \times\left(1-\Sigma_{i} p_{i}^{2}\right)$, where $p$ is the observed frequency of the $i$ th allele (43). Allelic richness was estimated as the mean number of alleles per locus (15) for a standardized sample size of 21 using rarefaction (28) as described by Petit et al. (51). To test whether groups of samples differed for allelic richness and gene diversity, we used FSTAT version 2.9.3.2 (24). $P$ values for testing the significance of the pairwise comparisons were obtained after 1,000 permutations.

The degree of population subdivision among host populations was assessed using pairwise $\Phi_{\mathrm{ST}}$. As the distance measure we used the sum of squared size differences $\left(R_{\mathrm{ST}}\right)$ between two haplotypes (56). Significance of the fixation indices $\left(\Phi_{\mathrm{ST}}\right.$ statistics, analogous to $F_{\mathrm{ST}}$ ) was tested using 1,023 permutations by a nonparametric approach (17). This analysis was conducted using the program ARLEQUIN version 3.11 (Zoological Institute, Department of Biology, University of Bern, Switzerland) (16).

Hardy-Weinberg and gametic equilibrium tests. To determine the mating system in different host populations, we first tested for Hardy-Weinberg equilibrium (HWE) using a measure analogous to the Fisher exact test (26). The $P$ values were obtained using a Markov chain Monte Carlo (MCMC) approach, generating an exact probability distribution not biased by rare alleles (53). The HWE test was performed using the program ARLEQUIN version 3.11 (16). Inbreeding, a possible cause of deviation from $\mathrm{HWE}$ was quantified based on measures of $\mathrm{F}_{I S}$ (60) to test for a significant deficit or excess of heterozygotes (when compared with HWE expectations), calculated with ARLEQUIN version 3.11 (16). Significance was assessed with 1,000 permutations.

We also tested for gametic disequilibrium (GD) using a multilocus association test (7). The hypothesis that genotypes at one locus are independent from genotypes at another locus was tested using Fisher's exact test (20) based on an MCMC algorithm, with 1,000 batches and 1,000 iterations/batch (7). This test was implemented by GENEPOP version 3.4 (Institut des Sciences de l'Evolution, Université Montpellier 2, Montpellier, France) (53). Two loci were considered in GD when their associated $P$ value was $\leq 0.05$. We also measured the index of association $\left(I_{A}\right)(38)$. We tested the hypothesis of complete panmixia by comparing the observed data set to data sets in which an infinite amount of sex and recombination has been imposed on the data by randomly shuffling the alleles amongst individuals independently for each locus. This test was implemented using MULTILOCUS version 1.3 (Department of Biology, Imperial College, Silwood Park, UK) (1), testing for significance with 1,000 randomizations and fixing missing data during randomizations.
Test for admixture or hidden population structure. Departures from HWE and gametic equilibrium observed in some populations of $R$. solani AG-1 IA could be caused by a Wahlund effect (i.e., population admixture). To determine whether any individuals in a sample were immigrants with respect to their reference geographical population, we used an assignment test performed with a Bayesian statistical model (52) implemented by STRUCTURE version 2.2 (Department of Human Genetics, University of Chicago) (52). This program calculates the membership coefficients to each of the populations $(\hat{Q})$ of every multilocus genotype sampled (which were assigned a priori to their reference populations). By including this a priori information, genotypes in the sample are assigned probabilistically to their reference population, or jointly to two or more populations if their genotypes indicate admixture. We performed 10 runs of MCMC simulations, with initial burning length of 10,000 , followed by 100,000 iterations. Parameters were set using $\mathrm{K}=3$ clusters, admixture model, and $\mathrm{F}_{\mathrm{ST}}$ values previously calculated with ARLEQUIN 3.2 (16).

Demographic parameters and historical migration. The effective population sizes and the historical migration rates between rice- and soybean-infecting populations were inferred using a maximum likelihood test based on the MCMC method implemented in MIGRATE version 2.3 (Department of Biological Science, Florida State University, Tallahassee, FL) (5). MIGRATE is based on the coalescent theory and uses a maximum likelihood approach to estimate effective population sizes and a migration matrix (6). It allows for estimation of asymmetrical migration between population pairs. The data type chosen was microsatellite data with Brownian motion, assuming the step-wise mutation model. A single run consisted of five replicates of 10 initial short chains and five long final chains, and static heating scheme with four temperatures $(1.0,1.3,2.6$, and 3.9). Initial chains were performed with 1,000 samples and a sampling interval of 20 (20,000 steps), with 1,000 trees recorded per short sample. The final five chains were carried out with 5,000 samples, sampling interval of 20 (200,000 steps), burn-in period of 10,000, and 10,000 trees recorded per long chain. The confidence interval for theta $(\theta)$ and migration parameter $M$ was calculated using a percentile approach.

Cross pathogenicity. The diseased leaf area was assessed on detached tissues of both rice and soybean using the image analysis software ASSESS from APS (ASSESS: Image Analysis Software for Plant Disease Quantification; L. Lamari, Department of Plant Science, University of Manitoba, Winnipeg, Manitoba, Canada). Analyses of variance were performed using the SAS statistics software package (version 9.1 of the SAS System for Windows; SAS Institute Inc., Cary, NC). Using PROC MIXED and CONTRAST statements, we evaluated two contrasts of interest for each experiment: (i) inoculated versus noninoculated treatments, and (ii) rice-derived versus soybean-derived isolates.

\section{RESULTS}

Microsatellite information content, gene and genotype diversity. All loci were polymorphic. The number of alleles observed per locus ranged from 4 to 12 . Allele frequencies were not evenly distributed for each locus. As a general trend, each locus had one or two alleles with frequencies higher than $20 \%$. Private alleles were found in all populations for all loci, except for TC02. Seven private alleles ( $15 \%$ of the total number of alleles per population) were found in the rice-infecting population from Texas, 17 (32\%) in the soybean-infecting population, and nine (17\%) in the rice-infecting population from Louisiana.

One hundred and fifty-four distinct multilocus genotypes were found among the 232 isolates assayed in the three populations (Table 1). None were shared among populations. Clonality was 
higher in the soybean-infecting population from Louisiana (around 50\%). This population also presented a significantly lower genotypic diversity index. Conversely, the rice-infecting population from Louisiana was the most diverse, presenting the lowest clonal fraction (2\%), the highest genotypic diversity, and genotypes were distributed more evenly (evenness $=0.96$ ). The rice-infecting population from Texas had a clonal fraction of 0.52 and a genotypic diversity index of 17.3 (evenness $=0.60$ ). These genotypic diversity values, however, are not directly comparable with the Louisiana populations because the Texas population was sampled from six different rice fields along a transect of a few hundred kilometers, while the Louisiana populations were from two single fields separated by $80 \mathrm{~km}$.

All 154 genotypes of $R$. solani AG-1 IA were heterozygous for at least one locus. The expected heterozygosity $\left(\mathrm{H}_{\mathrm{E}}=\right.$ Nei's unbiased gene diversity) varied from 0.55 to 0.63 across the two populations from Louisiana (Table 1). The overall allelic richness was 5.0. Nei's gene diversity values and mean allelic richness were not significantly different $(P<0.05)$ between the two populations from Louisiana.

Population differentiation. Pairwise analysis of population differentiation indicated that populations from rice were not differentiated $\left(\Phi_{\text {ST }}\right.$ values were not significantly different from zero) (Table 2). The highest amount of population differentiation was observed between the two pairs of host-distinct populations, i.e., the comparisons between the soybean-infecting population from Louisiana and the rice-infecting populations from either Louisiana or Texas $\left(\Phi_{\mathrm{ST}}\right.$ values varying from 0.39 to 0.41 , both significantly different from zero). Additional comparisons with a finer-scale subsample from Texas $(\mathrm{N}=8$ genotypes from Liberty County; data not shown) indicated the same level of subdivision between the allopatric rice- and soybean-infecting populations $\left(\Phi_{\mathrm{ST}}=0.40, P \leq 0.001\right)$ or no subdivision between the two allopatric rice-infecting populations $\left(\Phi_{\mathrm{ST}}=0.04^{\mathrm{NS}}, P=0.06\right)$. This was evidence that the pattern observed on the larger spatial scale reflects also the finer spatial scale.

Hardy-Weinberg and gametic equilibrium tests. Results from the Hardy-Weinberg equilibrium tests are presented in Table 3. The rice-infecting population from Texas had most of the loci under HWE proportions (7 of 10 loci). In contrast, the rice- and soybean-infecting populations from Louisiana showed half or more than half of the loci out of the equilibrium expected proportions. Most of the loci that were not under the expected proportions showed a significant excess of homozygotes (data not shown). Only the rice-infecting population from Louisiana had a significant $\mathrm{F}_{I S}(0.18 ; P \leq 0.01)$.

Significant GD was found for both rice- and soybean-infecting populations. However, $I_{A}$ values varied among populations (Table $3)$. The soybean-infecting population from Louisiana had the highest $I_{A}$ and also the highest proportion of loci with significant associations. In contrast, the rice-infecting population from
Louisiana showed the lowest $I_{A}$ and only nine pairs of loci with significant disequilibrium.

We tested the hypothesis that the observed gametic and HWE was due to the presence of clonal lineages (3). We performed a second clone correction by pooling multilocus genotypes differing by only single-step mutations at single loci (data not shown). Eleven genotypes belonging to similar clonal lineages were found in the soybean-infecting population from Louisiana and three in the rice-infecting population from Louisiana. No clonal lineages were found among the clone-corrected rice-infecting population from Texas. After removing these putative clonal lineages, the $I_{A}$ value decreased slightly and the number of locus pairs at significant disequilibrium dropped from 28 to 22 for the soybeaninfecting population. The exact test for HWE showed that five loci were in equilibrium, instead of three previously found for the original clone-corrected data set. Only a slight decrease in the $I_{A}$

TABLE 2. Measures of differentiation among rice- and soybean-infecting populations of Rhizoctonia solani anastomosis group-1 IA from southern United States based on $\Phi_{\mathrm{ST}}$ values ${ }^{\mathrm{z}}$

\begin{tabular}{lcc}
\hline Populations & Texas rice-infecting & Louisiana rice-infecting \\
\hline Louisiana rice-infecting & $0.013 \mathrm{~ns}$ & \\
Louisiana soybean-infecting & $0.408 * * *$ & $0.386 * * *$ \\
\hline
\end{tabular}

${ }^{\mathrm{z}}$ Distances were computed as the sum of squared size differences between two haplotypes (56). Significance values: ns indicates nonsignificant at $P \leq$ 0.05 and $* * *$ indicates $P \leq 0.001$ based on 1,023 permutations.

TABLE 3. Tests for random association of alleles within each locus and between pairs of loci in rice- and soybean-infecting populations of Rhizoctonia solani anastomosis group-1 IA from southern United States

\begin{tabular}{lcccccc}
\hline Population & $\begin{array}{c}\text { Number of } \\
\text { loci in } \mathrm{HWE}^{\mathrm{v}}\end{array}$ & $F_{\mathrm{IS}^{\mathrm{w}}}$ & $P$ & $\mathrm{I}_{\mathrm{A}}{ }^{\mathrm{x}}$ & $P^{\mathrm{y}}$ & $\mathrm{GD}^{\mathrm{z}}$ \\
\hline $\begin{array}{l}\text { Louisiana rice- } \\
\text { infecting } \\
\begin{array}{l}\text { Louisiana soybean- } \\
\quad \text { infecting }\end{array}\end{array}$ & $5 / 10$ & 0.18 & 0.00 & 0.385 & 0.001 & $9 / 45$ \\
$\begin{array}{l}\text { Texas rice- } \\
\text { infecting }\end{array}$ & $3 / 10$ & 0.02 & 0.43 & 1.895 & $<0.001$ & $28 / 45$ \\
& $7 / 10$ & -0.004 & 0.50 & 1.096 & $<0.001$ & $9 / 45$ \\
\hline
\end{tabular}

${ }^{\mathrm{v}}$ HWE test performed according to an exact test analogous to Fisher's exact test, using a Markov chain with forecasted length of 100,000 (26).

${ }^{\text {w }}$ Population-specific $F_{\text {IS }}$ indices and $P$ values calculated based on 1,023 permutations using ARLEQUIN 3.2 (16).

${ }^{x} \mathrm{I}_{\mathrm{A}}$ is an index of multilocus gametic disequilibrium (38).

y Testing $\mathrm{H}_{\mathrm{O}}=$ complete panmixia based on 1,000 randomizations; for diploid data, the two alleles at a locus are shuffled together (associations between alleles at a locus are maintained in the randomized data sets); thus, the test is purely for associations between loci (1).

z Pairs of loci at significant disequilibrium according to the Fisher's exact test (probability test) using a Markov chain with 1,000 batches and 1,000 iterations/batch, implemented by GenePop 3.4 (53).


States

\begin{tabular}{|c|c|c|c|c|c|c|c|}
\hline Host populations & Sample size (N) & $\begin{array}{c}\text { Number of } \\
\text { genotypes }\end{array}$ & Clonal fraction & $\begin{array}{c}\text { Genotypic } \\
\text { diversity }\left(\mathrm{G}_{\mathrm{O}}\right)^{\mathrm{uv}}\end{array}$ & Evenness ${ }^{\mathrm{vw}}$ & $\mathrm{H}_{\mathrm{E}}^{\mathrm{xy}}$ & $\begin{array}{c}\text { Allelic } \\
\text { richness }^{\mathrm{xz}}\end{array}$ \\
\hline Louisiana rice-infecting & 85 & 83 & 0.02 & $79.4 \mathrm{a}$ & $0.96 \mathrm{a}$ & 0.63 & 4.93 \\
\hline Louisiana soybean-infecting & 86 & 42 & 0.51 & $24.3 \mathrm{~b}$ & $0.58 \mathrm{~b}$ & 0.55 & 5.06 \\
\hline \multirow[t]{2}{*}{ Texas rice-infecting } & 61 & 29 & 0.52 & $17.3 \mathrm{~b}$ & $0.60 \mathrm{~b}$ & 0.55 & 4.78 \\
\hline & $\Sigma=232$ & $\Sigma=154$ & & & & & \\
\hline
\end{tabular}

u Stoddart and Taylor's genotypic diversity $(57,58)$.

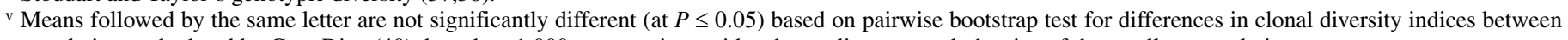
populations calculated by GenoDive (40), based on 1,000 permutations with subsampling to match the size of the smallest population.

${ }^{\text {w }} G_{\mathrm{O}}$ scaled by the maximum number of expected genotypes; an evenness value $=1.0$ indicates that all genotypes have equal frequencies.

x Nei's unbiased gene diversity (43), also known as expected heterozygosity, averaged over all loci, corrected for the sample size.


permutations.

${ }^{\text {z }}$ Calculated according to El Mousadik and Petit (15). 
was found in the rice-infecting population from Louisiana. The HWE exact test and the number of pairs of loci showing significant disequilibrium remained the same.

Test for admixture or hidden population structure. More than $99.2 \%$ of the isolates were assigned to the populations from where they were originally sampled (probability of inclusion in the proper cluster $>0.9)$. Under this model, six isolates were assigned with probabilities less than 0.9 ( 0.65 to 0.86$)$, but none of those isolates could be assigned to more than one cluster, indicating that admixture was not occurring.

Demographic parameters and historical migration. Though no evidence for current gene flow was detected between populations from different hosts (Table 2), there was historical migration between those populations (Fig. 1). The highest migration rates were found between the two rice-infecting populations $\left(4 \mathrm{Nm}_{3 \rightarrow 1}=1.38\right.$ from Texas rice-infecting to Louisiana riceinfecting; backwards $4 \mathrm{Nm}_{1 \rightarrow 3}=1.52$ ). Intermediate migration rates were found between the rice- and soybean-infecting populations from Louisiana, but the migration rates were asymmetrical $\left(4 \mathrm{Nm}_{1 \rightarrow 2}=1.12\right.$ from Louisiana rice-infecting to Louisiana soybean-infecting; backwards $4 \mathrm{Nm}_{2 \rightarrow 1}=0.74$ ). Symmetrical migration was indicated between the rice-infecting population from Texas and the soybean-infecting population from Louisiana, with around 0.60 migrants exchanged per generation (Fig. 1). The effective population sizes estimates $(\theta)$ were quite similar for all three populations (Fig. 1). The historical migration context is depicted in Figure 1.

Cross pathogenicity test. Soybean-derived and rice-derived isolates were cross pathogenic for both hosts (Table 4). However, isolates were more aggressive on their host of origin (significant contrasts of means between soybean and rice groups at $P<$ 0.0001 ), even after removing one outlier isolate within each group of host-distinct isolates (Kat E10, multilocus SSR genotype \#34 and Rita B06, \#105) $(P<0.025)$.

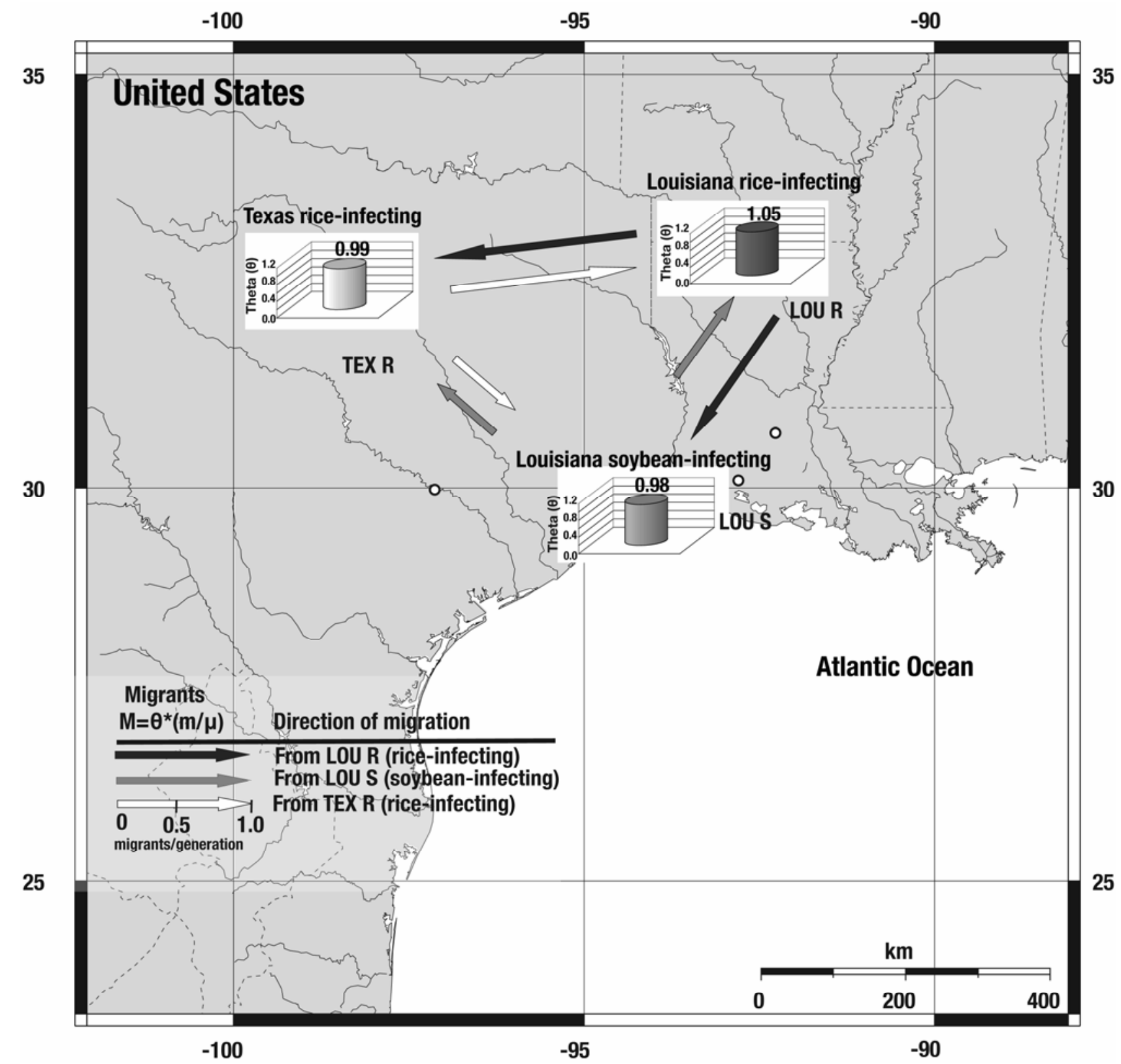

Fig. 1. Estimates of demographic parameters from the divergence among rice- and soybean-infecting populations of Rhizoctonia solani AG-1 IA from southern United States based on variation in 10 microsatellite loci. Theta values are a measure of effective population size (for diploids theta $=4 N \mathrm{e} \mu$, where $N \mathrm{e}=$ effective population size and $\mu=$ mutation rate inferred for each locus). Migration between geographical populations was estimated using an isolation with migration model. Both theta values and migration rates were estimated using MIGRATE 2.3 (6). Values represent the average across 10 loci. The directions for migration between sink and source populations are indicated by arrows. 


\section{DISCUSSION}

Evidence of genetic differentiation between rice- and soybean-infecting populations. Significant population subdivision was found between rice- and soybean-infecting populations, both in sympatry and in allopatry. Although the Texas population was sampled 11 years earlier than the Louisiana one, the temporal difference apparently did not affect the level of subdivision between these two rice-infecting populations as no subdivision was observed (Table 2). There was further evidence of genetic differentiation between rice- and soybean-infecting populations based on the Bayesian analyses for admixture. No admixed genotype was detected between the two host populations. Although current levels of gene flow were consistent with population differentiation, historical migration was detected between rice- and soybean-infecting populations. We found evidence for asymmetric historical migration from the rice- to the soybean-infecting population. As a donor population, the rice-infecting population contributed nearly twice as many migrants to the soybean-infecting population. While the overall gene flow was low, this directional asymmetry is evidence that the soybean-infecting population from Louisiana may be derived from a rice-infecting population. Rice- and soybean-derived isolates of $R$. solani AG-1 IA were cross pathogenic to both rice and soybean, but more aggressive on their original host. This differential response in aggressiveness observed for the two host populations of $R$. solani AG-1 IA isolates could be explained by divergence through ecological adaptation to each host $(29,34)$. We hypothesize that the current soybean-infecting population of $R$. solani AG-1 IA has arisen through selection and adaptation from an originally riceinfecting population. As the rice-adapted and the soybean-adapted populations are still cross pathogenic, we postulate that this ecological adaptation could be a recent event, perhaps dating back to the introduction of both rice and soybean crops and followed by the expansion of these crops in the southern United States in the early 20 th century $(30,55)$. In fact, rice was a major crop in south Louisiana before soybean was grown to any extent (46). Soybeans did not become an important cash crop in Louisiana until the 1960s (41). In the 1960s, soybean became the most common rotation crop with rice (previously rotation was mainly native grass pasture) (46).

Under the scenario of rather low gene flow between rice- and soybean-infecting populations (i.e., the migration rates $M$ detected were either less than or close to one, which is the minimum amount needed to prevent populations from diverging due to genetic drift [27]), it becomes easier for populations to diverge through selection. This is further evidence that speciation driven by host specialization may be underway between rice- and soybean-infecting populations of $R$. solani AG-1 IA. Besides host specialization, divergence could have arisen through two other alternative scenarios: (i) due to selection imposed by different environmental factors such as the cropping system, e.g., rice is cropped under flooded conditions and soybean on dry land areas $(36,41)$; or (ii) divergence could also occur if soybean populations originated from another crop or location and were not descended from local rice populations in Louisiana. This seems unlikely as the rice-soybean rotation is the normal rotation scheme in Louisiana and $R$. solani AG-1 $1 \mathrm{~A}$ is rarely transmitted by soybean seeds (46).

Reproductive modes. Most fungal populations probably occupy an intermediate position between complete asexual reproduction and panmixia, with some clonal reproduction and some recombination (3). We observed that the two host distinct populations from Louisiana differed in their reproductive mode. The rice-infecting population from Louisiana had the lowest clonal fraction, half of the loci in HWE, a low proportion of locus pairs

TABLE 4. Cross pathogenicity test of rice- and soybean-infecting isolates from distinct multilocus simple sequence repeats (SSR) genotypes of Rhizoctonia solani anastomosis group-1 IA from southern United States ${ }^{\mathrm{Z}}$

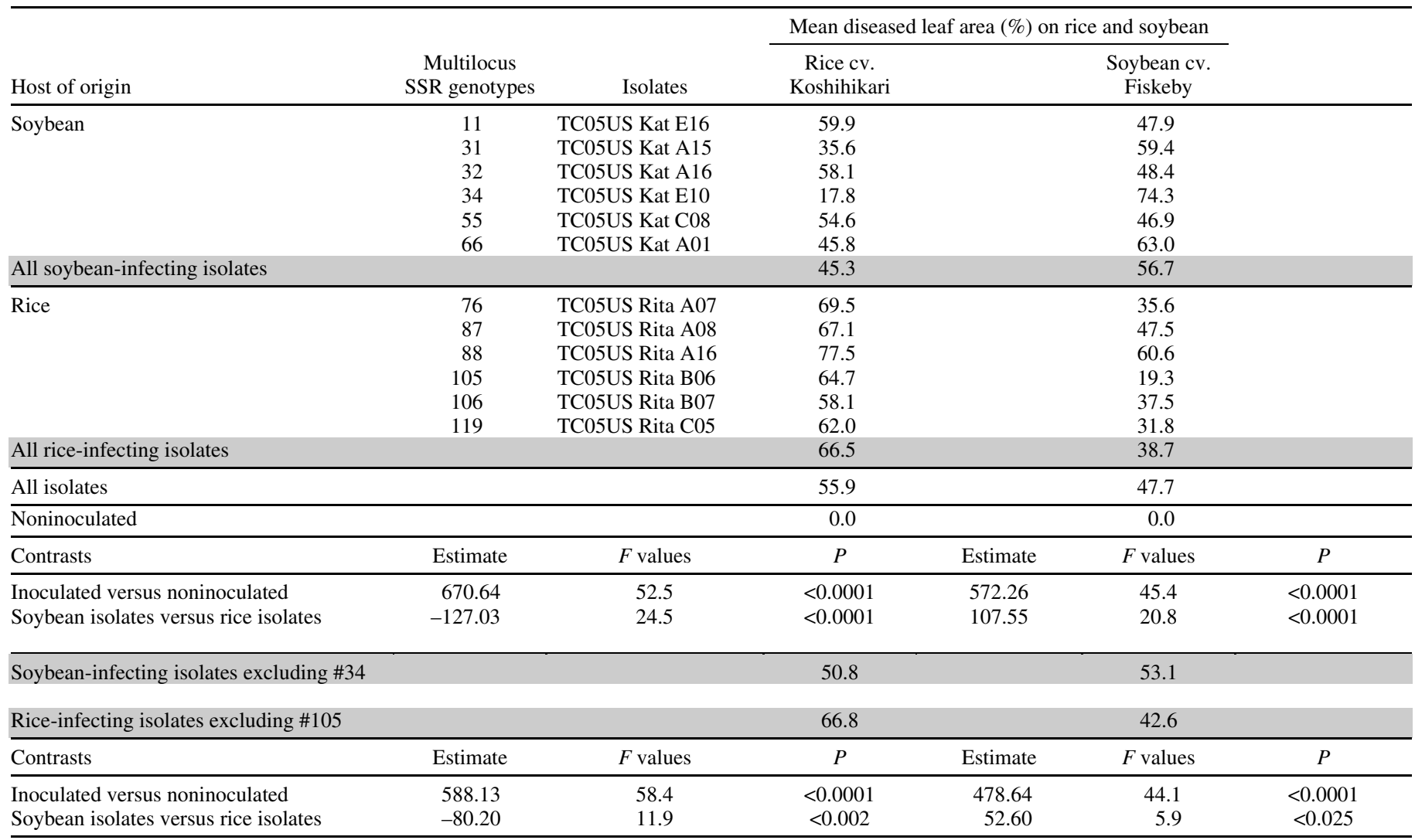

${ }^{\mathrm{z}}$ The rice and soybean experiments were run independently. The experiments were arranged in randomized complete block design, with five blocks for rice and soybean. Shading indicates mean diseased leaf area for each group of isolates. 
in GD and the lowest $I_{A}$ value. However, this rice-infecting population exhibited a significant degree of inbreeding within the sexual component of the reproduction. Inbreeding does not necessarily reflect a homothallic mating system, but it could be the first hint of homothallism in this fungus. Our interpretation of these findings is that the rice-infecting population in Louisiana has a recombining population structure characterized by few clones, but undergoes significant inbreeding. Our results also support recombination for the rice-infecting population from Texas, in agreement with former analyses based on restriction fragment length polymorphism data (54). We propose a mixed reproductive mode for these populations, which includes recombination events followed by clonal expansion during the growing season.

Though soybean-infecting $R$. solani AG-1 IA has been considered to have a predominantly sexual reproduction system because sexual fruiting structures (hymenia and basidiospores) are reported as the primary inoculum on soybean fields $(18,19$, 31,49 ), we have not found evidence for predominantly sexual reproduction. Three out of six soybean-infecting populations from Brazil had a similar high degree of clonality (11). The other example of a sexually reproducing Rhizoctonia species with a high degree of clonality within field populations is the homothallic $R$. solani AG-3 on tobacco (9).

Taking all of the evidence gathered to date, including the nested cladistic analysis on ITS-5.8S region (10), current data on population subdivision based on microsatellite loci, and the finding of higher aggressiveness of isolates on their original host, we hypothesize that rice- and soybean-infecting populations of $R$. solani AG-1 IA represent subdivided populations that still exchange genes, but are becoming progressively more distinct due to selection for host specialization. We speculate that the pathogen emerged in the southern United States first on rice and then shifted onto soybeans after soybeans were introduced into the southern United States. The finding of higher clonality in the soybean population suggests that particular clones were favored on this host compared with the rice host. The extent of differentiation and specialization of $R$. solani AG-1 IA populations is probably dependent on the degree of relatedness of their hosts of origin. For example, when sympatric Venezuelan populations of $R$. solani AG-1 IA from two distinct hosts but within the same plant family (i.e., rice and maize, both from the Poaceae) were compared, the extent of differentiation was much lower $\left(\Phi_{\mathrm{ST}}=\right.$ 0.17 to 0.22$)$ (23) than observed in this study $\left(\Phi_{\mathrm{ST}}= \pm 0.40\right)$, which included populations from two distinct families, i.e., Poaceae and Fabaceae.

\section{ACKNOWLEDGMENTS}

The first author acknowledges the efforts of M. C. Rush and members of his laboratory staff for sampling the rice and soybean fields in Louisiana before the devastating flooding of Hurricanes Katrina and Rita. This work was partially funded by an ETH grant (TH-16/06-1) to P. C. Ceresini. The statistical analyses on migration patterns were carried out using the Computational Biology Service Unit from Cornell University, which is partially funded by Microsoft Corporation.

\section{LITERATURE CITED}

1. Agapow, P.-M., and Burt, A. 2001. Indices of multilocus linkage disequilibrium. Mol. Ecol. Notes 1(1-2):101-102.

2. Amos, W., Hoffman, J. I., Frodsham, A., Zhang, L., Best, S., and Hill, A. V. S. 2007. Automated binning of microsatellite alleles: Problems and solutions. Mol. Ecol. Notes 7(1):10-14.

3. Anderson, J. B., and Kohn, L. M. 1995. Clonality in soilborne, plantpathogenic fungi. Annu. Rev. Phytopathol. 33:369-391.

4. Baker, C. J., Harrington, T. C., Krauss, U., and Alfenas, A. C. 2003. Genetic variability and host specialization in the Latin American clade of Ceratocystis fimbriata. Phytopathology 93:1274-1284.

5. Beerli, P., and Felsenstein, J. 1999. Maximum-likelihood estimation of migration rates and effective population numbers in two populations using a coalescent approach. Genetics 152:763-773.
6. Beerli, P., and Felsenstein, J. 2001. Maximum likelihood estimation of a migration matrix and effective population sizes in $n$ subpopulations by using a coalescent approach. Proc. Natl. Acad. Sci. 98:4563-4568.

7. Brown, A. H. D., Feldman, M. W., and Nevo, E. 1980. Multilocus structure of natural populations of Hordeum spontaneum. Genetics 96:523536.

8. Bucheli, E., Gautschi, B., and Shykoff, J. A. 2000. Host-specific differentiation in the anther smut fungus Microbotryum violaceum as revealed by microsatellites. J. Evol. Biol. 13:188-198.

9. Ceresini, P. C., Shew, H. D., James, T. Y., Vilgalys, R. J., and Cubeta, M. A. 2007. Phylogeography of the solanaceae-infecting Basidiomycota fungus Rhizoctonia solani AG-3 based on sequence analysis of two nuclear DNA loci. BMC Evol. Biol. 13:163.

10. Ciampi, M. B., Kuramae, E. E., Fenille, R. C., Meyer, M. C., Souza, N. L., and Ceresini, P. C. 2005. Intraspecific evolution of Rhizoctonia solani AG-1 IA associated with soybean and rice in Brazil based on polymorphisms at the ITS-5.8S rDNA operon. Eur. J. Plant Pathol. 113:183-196.

11. Ciampi, M. B., Meyer, M. C., Costa, M. N., Jr., Zala, M., McDonald, B. A., and Ceresini, P. C. 2008. Genetic structure of populations of Rhizoctonia solani anastamosis group-1 IA from soybean in Brazil. Phytopathology 98:932-941.

12. Costa-Souza, E., Kuramae, E. E., Nakatani, A. K., Basseto, M. A., Prabhu, A. S., and Ceresini, P. C. 2007. Caracterização citomorfológica, cultural, molecular e patogênica de Rhizoctonia solani Kühn associado ao arroz em Tocantins, Brasil. Summa Phytopathol. 33:129-136.

13. Couch, B. C., Fudal, I., Lebrun, M.-H., Tharreau, D., Valent, B., van Kim, P., Notteghem, J.-L., and Kohn, L. M. 2005. Origins of host-specific populations of the blast pathogen Magnaporthe oryzae in crop domestication with subsequent expansion of pandemic clones on rice and weeds of rice. Genetics 170:613-630.

14. Couch, B. C., and Kohn, L. M. 2002. A multilocus gene genealogy concordant with host preference indicates segregation of a new species, Magnaporthe oryzae, from M. grisea. Mycologia 94:683-693.

15. El Mousadik, A., and Petit, R. J. 1996. High level of genetic differentiation for allelic richness among populations of the argan tree [Argania spinosa (L.) Skeels] endemic to Morocco. Theor. Appl. Genet. 92:832839.

16. Excoffier, L., Laval, G., and Schneider, S. 2005. Arlequin (version 3.0): An integrated software package for population genetics data analysis. Evol. Bioinform. Online 1:47-50.

17. Excoffier, L., Smouse, P. E., and Quattro, J. M. 1992. Analysis of molecular variance inferred from metric distances among DNA haplotypes: Application to human mitochondrial DNA restriction data. Genetics 131:479-491.

18. Fenille, R. C., Ciampi, M. B., Kuramae, E. E., and Souza, N. L. 2003. Identification of Rhizoctonia solani associated with soybean in Brazil by rDNA-ITS sequences. Fitopatol. Bras. 28:413-419.

19. Fenille, R. C., Souza, N. L., and Kuramae, E. E. 2002. Characterization of Rhizoctonia solani associated with soybean in Brazil. Eur. J. Plant Pathol. 108:783-792.

20. Garnier-Gere, P., and Dillmann, C. 1992. A computer program for testing pairwise linkage disequilibria in subdivided populations. J. Hered. $83: 239$.

21. Glaubitz, J. C. 2004. Convert: A user-friendly program to reformat diploid genotypic data for commonly used population genetic software packages. Mol. Ecol. Notes 4:309-310.

22. Gonzalez, D., Carling, D. E., Kuninaga, S., Vilgalys, R., and Cubeta, M. A. 2001. Ribosomal DNA systematics of Ceratobasidium and Thanatephorus with Rhizoctonia anamorphs. Mycologia 93:1138-1150.

23. González-Vera, A. D., Bernardes-de-Assis, J., Zala, M., McDonald, B. A., and Ceresini, P. C. 2008. Population genetics of the rice- and maizeinfecting pathogen Rhizoctonia solani AG 1-IA from Venezuela. Page 51 in: Abstr. 4th Int. Symp. on Rhizoctonia. Berlin, Germany.

24. Goudet, J. 1995. FSTAT (Version 1.2): A computer program to calculate F-statistics. J. Hered. 86:485-486.

25. Grunwald, N. J., Goodwin, S. B., Milgroom, M. G., and Fry, W. E. 2003. Analysis of genotypic diversity data for populations of microorganisms. Phytopathology 93:738-746.

26. Guo, S. W., and Thompson, E. A. 1992. Performing the exact test of Hardy-Weinberg proportions for multiple alleles. Biometrics 48:361-372.

27. Hartl, D. L., and Clark, A. G. 1997. Principles of Population Genetics. 3rd ed. Sinauer Associates, Sunderland, MA.

28. Hurlbert, S. 1971. The nonconcept of species diversity: a critique and alternative parameters. Ecology 52:577-586

29. Huyse, T., Poulin, R., and Theron, A. 2005. Speciation in parasites: A population genetics approach. Trends Parasitol. 21:469-475.

30. Hymowitz, T. 1995. Soybean: Glycine max (Leguminosae: Papilionoidae). Pages 261-266 in: Evolution of Crop Plants. J. Smarzz and N. W. Simmonds, eds. Longman Scientific \& Technical, Harlow. 
31. Jones, R. K., and Belmar, S. B. 1989. Characterization and pathogenicity of Rhizoctonia spp. isolated from rice, soybean, and other crops grown in rotation with rice in Texas. Plant Dis. 73:1004-1010.

32. Ko, W., and Hora, F. 1971. A selective medium for the quantitative determination of Rhizoctonia solani in soil. Phytopathology 61:707-710.

33. Kobayashi, T., Mew, T. W., and Hashiba, T. 1997. Relationship between incidence of rice sheath blight and primary inoculum in the Philippines: Mycelia in plant debris and sclerotia. Ann. Phytopathol. Soc. Jpn. 63:324327.

34. Kohn, L. M. 2005. Mechanisms of fungal speciation. Annu. Rev. Phytopathol. 43:279-308.

35. Linde, C. C., Zala, M., Paulraj, R. S. D., McDonald, B. A., and Gnanamanickam, S. S. 2005. Population structure of the rice sheath blight pathogen Rhizoctonia solani AG-1 IA from India. Eur. J. Plant Pathol. 112:113-121.

36. Linscombe, S. D., Saichuk, J. K., Seilhan, K. P., Bollich, P. K., and Funderburg, E. R. 1999. General agronomic guidelines. Pages 4-11 in: Louisiana Rice Production Handbook. C. A. Hollier, ed. Louisiana State University Agricultural Center, Louisiana Cooperative Extension Service, Pub. No. 2321

37. Manly, B. F. J. 1991. Randomization and Monte Carlo Methods in Biology. Chapman \& Hall, London.

38. Maynard Smith, J., Smith, N. H., O’Rourke, M., and Spratt, B. G. 1993. How clonal are bacteria? Proc. Natl. Acad. Sci. 90:4384-4388.

39. McDonald, B. A., and Linde, C. 2002. Pathogen population genetics, evolutionary potential, and durable resistance. Annu. Rev. Phytopathol. 40:349-379.

40. Meirmans, P. G., and Van Tienderen, P. H. 2004. GenoType and GenoDive: Two programs for the analysis of genetic diversity of asexual organisms. Mol. Ecol. Notes 4:792-794.

41. Morrison, W. C. (ed.) 1996. Louisiana Soybean Handbook. Louisiana State University Agricultural Center, Louisiana Cooperative Extension Service, Pub. No. 2624.

42. Naito, S. 2006. Ecological studies on teleomorphic and anamorphic stages in Rhizoctonia fungi. J. Gen. Plant Pathol. 72:400-403.

43. Nei, M. 1978. Estimation of average heterozygosity and genetic distance from a number of individuals. Genetics 89:538-590.

44. Ogliari, J. B., Boscariol, R. L., and Camargo, L. E. A. 2000. Optimization of PCR amplification of maize microsatellite loci. Gen. Mol. Biol. 23:395-398.

45. Ogoshi, A. 1987. Ecology and pathogenicity of anastomosis and intraspecific groups of Rhizoctonia solani Kühn. Annu. Rev. Phytopathol. 25:125-143.

46. O’Neill, N. R., Rush, M. C., Horn, N. L., and Carver, R. B. 1977. Aerial blight of soybeans caused by Rhizoctonia solani. Plant Dis. Rep. 61:713717.

47. Oniki, M., Ogoshi, A., and Araki, T. 1986. Development of the perfect state of Rhizoctonia solani Kühn AG-1. Ann. Phytopathol. Soc. Jpn. 52:169-74.

48. Parker, I. M., and Gilbert, G. S. 2004. The evolutionary ecology of novel plant-pathogen interactions. Annu. Rev. Ecol. Evol. S. 35:675-700.

49. Pascual, C. B., and Hyakumachi, M. 2000. Distribution of vegetatively compatible populations of Rhizoctonia solani AG-1 IA in a field planted with different host species. J. Gen. Plant Pathol. 66:206-209.

50. Pascual, C. B., Toda, T., Raymondo, A. D., and Hyakumachi, M. 2000. Characterization by conventional techniques and PCR of Rhizoctonia solani isolates causing banded leaf sheath blight in maize. Plant Pathol. 49:108-118.

51. Petit, R. J., El Mousadik, A., and Pons, O. 1998. Identifying populations for conservation on the basis of genetic markers. Conserv. Biol. 12:844855.

52. Pritchard, J. K., Stephens, M., and Donnelly, P. 2000. Inference of population structure using multilocus genotype data. Genetics 155:945959.

53. Raymond, M., and Rousset, F. 1995. GENEPOP (Version 1.2): Population genetics software for exact tests and ecumenicism. J. Hered. 86:248-249.

54. Rosewich, U. L., Pettway, R. E., McDonald, B. A., and Kistler, H. C. 1999. High levels of gene flow and heterozygote excess characterize Rhizoctonia solani AG-1 IA (Thanatephorus cucumeris) from Texas. Fungal Genet. Biol. 28:148-159.

55. Sauer, J. D. 1993. Historical Geography of Crop Plants: A Select Roster. CRC Press, Boca Raton, FL.

56. Slatkin, M. 1995. A measure of population subdivision based on microsatellite allele frequencies. Genetics 139:457-462.

57. Stoddart, J. A. 1983. A genotypic diversity measure. J. Hered. 74:489-490.

58. Stoddart, J. A., and Taylor, J. F. 1988. Genotype diversity: Estimation and prediction in samples. Genetics 118:705-711.

59. Stukenbrock, E. H., Banke, S., Javan-Nikkhah, M., and McDonald, B. A. 2007. Origin and domestication of the fungal wheat pathogen Mycosphaerella graminicola via sympatric speciation. Mol. Biol. Evol. 24:398411.

60. Wright, S. 1965. The interpretation of population structure by F-statistics with special regard to systems of mating. Evolution 19:395-420.

61. Yang, X. B., Berggreen, G. T., and Snow, J. T. 1990. Seedling infection of soybean by isolates of Rhizoctonia solani AG-1, the causal agent of aerial blight and web blight of soybean. Plant Dis. 74:485-488.

62. Zala, M., McDonald, B. A., Bernardes de Assis, J., Ciampi, M. B., Storari, M., Peyer, P., and Ceresini, P. C. 2008. Highly polymorphic microsatellite loci in the maize- and rice-infecting fungal pathogen Rhizoctonia solani anastomosis group 1 IA. Mol. Ecol. Res. 8:686-689.

63. Zhan, J., Pettway, R. E., and McDonald, B. A. 2003. The global genetic structure of the wheat pathogen Mycosphaerella graminicola is characterized by high nuclear diversity, low mitochondrial diversity, regular recombination, and gene flow. Fungal Genet. Biol. 38:286-297. 